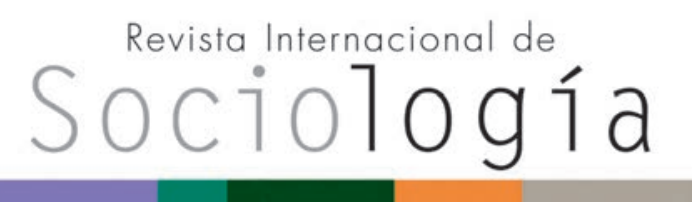

Revista Internacional de Sociología RIS vol. 77 (2), e127, abril-junio, 2019, ISSN-L:0034-9712 https://doi.org/10.3989/ris.2019.77.2.17.049

\section{INMIGRANTES \\ LATINOAMERICANOS EN LAS FUERZAS ARMADAS: DISCURSOS SOBRE NACIONALIDAD Y CIUDADANÍA}

\author{
JosÉ MARÍA ARRIBAS \\ UNED \\ jarribas@poli.uned.es \\ ORCID iD: https://orcid.org/0000-0002-6505-1365 \\ CONSUELO DEL VAL CID \\ UNED \\ cval@poli.uned.es \\ ORCID iD: https://orcid.org/0000-0001-7736-2825 \\ BeATRIz MAÑAs RamíREZ \\ UNED \\ bmanas@poli.uned.es \\ ORCID iD: https://orcid.org/0000-0003-4451-2844
}

Cómo citar este artículo / Citation: Arribas, J. M., C. del Val Cid y B. Mañas Ramírez. 2019. "Inmigrantes latinoamericanos en las fuerzas armadas: discursos sobre nacionalidad y ciudadanía". Revista Internacional de Sociología 77(2):e127. https://doi.org/10.3989/ris.2019.77.2.17.049

\section{RESUMEN}

Este artículo tiene por objeto estudiar el significado de nacionalidad y ciudadanía para un colectivo concreto: los inmigrantes latinoamericanos que trabajan en las Fuerzas Armadas españolas. El trabajo empírico, que tiene un enfoque cualitativo, se ha desarrollado mediante grupos de discusión en los que han participado militares inmigrantes en activo. El análisis del discurso permitirá observar las dimensiones y significados del sentimiento nacional y el sentido que para este colectivo tienen la nación y la ciudadanía. Finalmente, se identificarán una serie de posiciones que evidencian la complejidad del hecho nacional en un mundo de migraciones masivas, donde más que identidades simbólicas fuertes, se construyen otras moduladas por las estrategias y los proyectos vitales.

\section{Palabras Clave}

Grupos de discusión; Inmigración y ejército; Investigación cualitativa; Pertenencia nacional; Sentimiento nacional

\section{LATIN-AMERICAN IMMIGRANTS IN THE SPANISH ARMED FORCES: DISCOURSES ON NATIONALITY AND CITIZENSHIP}

Copyright: (C) 2019 CSIC. Este es un artículo de acceso abierto distribuido bajo los términos de la licencia de uso y distribución Creative Commons Reconocimiento 4.0 Internacional (CC BY 4.0).

Recibido: 28/03/2017. Aceptado: 04/06/2018

Publicado online: 04/06/2019

\section{Abstract}

This paper aims to study the meaning of "nationality" and "citizenship" for a specific group: Latin American immigrants working in the Spanish Armed Forces. The empirical work is based on a qualitative approach by conducting discussion groups formed by immigrant soldiers in regular service. By the discourse analysis we will observe several dimensions of the "national feeling", as well as the meanings of "nation" and "citizenship" that this group sustains. We will also identify a series of positions which show the complexity of the "national" meaning in a world of massive migrations where, more than strong symbolic identities, others closer to personal life strategies are being built.

\section{KEYWORDS}

Discussion groups; Immigration and Army; National be-longing; National feeling; Qualitative research. 


\section{INTRODUCCIÓN Y OBJETIVOS DE LA INVESTIGACIÓN}

El objetivo general que guía la investigación es comprender el proceso por el que la población inmigrante se convierte en población nacional. Partiendo de esta orientación genérica, nuestro trabajo empírico se centra exclusivamente en el estudio del discurso sobre nacionalidad y ciudadanía de un colectivo, el de los inmigrantes latinoamericanos alistados en las Fuerzas Armadas Españolas (FF.AA.), cuya vinculación con tales procesos es especialmente relevante por dos motivos. En primer lugar, Latinoamérica es el lugar de origen mayoritario entre los inmigrantes de nuestro país y, en segundo lugar, su dedicación profesional implica la participación en conflictos armados defendiendo los intereses nacionales de un país inicialmente diferente al suyo. Ello les sitúa, respecto al desarrollo de un sentido de pertenencia nacional, en una situación compleja y potencialmente distinta a la de la población militar autóctona.

Tras acercarnos teóricamente a la trayectoria de los conceptos de nacionalidad y ciudadanía, abordaremos el trabajo empírico: un estudio cualitativo con grupos de militares inmigrantes en activo en el ejército español. El análisis del discurso permitirá explicar las dimensiones, complejas y a veces contradictorias, que conforman ese sentido de pertenencia. Finalmente, identificaremos una serie de posiciones que ayudarán a articular y sintetizar los discursos colectivos sobre el sentimiento nacional.

\section{MARCO TEÓRICO: NACIONALIDAD, CIU- DADANÍA E INMIGRACIÓN}

El significante nación ha tenido diferentes significados a lo largo del tiempo. En pocos años, la nación ha pasado de considerarse un fenómeno natural basado en las características etnográficas y lingüísticas de una población a incorporar otros significados — realidad inventada, comunidad imaginada, relato- que aproximan la nación a un constructo ${ }^{1}$. En la actualidad, la idea de que la nación es una construcción imaginada por las élites intelectuales, políticas y administrativas de los Estados está cada vez más extendida en el ámbito académico (Pérez Vejo 2010; Schnapper 2001). En este sentido, el auge del construccionismo durante los años ochenta puede haber marcado un punto de inflexión en la consideración de la nación desde una realidad natural hasta una construcción política temporal susceptible al cambio $^{2}$. Este enfoque puede observarse en los trabajos clásicos de Elie Kedourie (1960), Ernest Gellner (1997), Benedict Anderson (1983) y Eric Hobsbawm ([1990] 2004), así como en publicaciones españolas más recientes (Álvarez Junco 2016; Fusi 2016; Pérez Vejo 2015; Cotarelo 2015; Romero y Furió 2015; Morales et al. 2013).
Desde una perspectiva histórica, la concepción republicana de nación adquiere un carácter político cuando, a finales del siglo XVIII, las luchas de independencia americana, la Revolución francesa y la resistencia a Napoleón fueron modelando las definiciones de nación y ciudadanía. Mientras en la tradición republicana es el pueblo soberano quien encarna la nación frente al Estado o al monarca, en el modelo alemán (Herder, Fitche) se prioriza la dimensión identitaria a través de elementos históricos, lingüísticos, etnográficos y también esencialistas, como el espíritu del pueblo (Volksgeist) o el alma colectiva. Es ahora cuando las naciones van a necesitar justificaciones del relato (Pérez Vejo 2015; Noiriel 2001) que expliquen los grandes mitos nacionales, labor en la que los intelectuales tendrán un importante papel ${ }^{3}$. Tal fue el caso americano, en el cual, según Pérez Vejo (2015), las élites de la Administración del Estado, en estrecha colaboración con el mundo de la cultura, fueron los verdaderos artífices de la nación americana.

La construcción de la nación se ha analizado también como un intento de modernizar la sociedad (Álvarez Junco 2016; Gellner 1997), de disolver las excesivas diferencias sociales y culturales de la sociedad tradicional integrándolas en una comunidad social y política más amplia. La diversidad del reino y del imperio dio paso a la unidad nacional y la nacionalidad comenzó a contemplarse como la personalidad de los grupos pertenecientes a un Estado. En este proceso, las comunicaciones, la escuela pública y las guerras que implicaban un enemigo común habrían favorecido un sentimiento compartido de identidad nacional en el que tan importante resultaba la comunidad de los vivos como la de los muertos. La religión, a través del culto a los ancestros, así como la escuela, como transmisora de la cultura nacional entre generaciones, habrían sido instituciones determinantes para la configuración de la nación moderna. Tal como observaron los sociólogos de la escuela durkheimiana, la nacionalidad sería el cordón umbilical que une al individuo con el Estado ${ }^{4}$, indicando el vínculo jurídico y político de esa relación.

Pero la construcción nacional necesita, además, que sus miembros acepten un sistema de leyes y de normas, un "consenso moral" (Schnapper 2001) que aporte coherencia política e integración. En este sentido, la Revolución Francesa colocó en el plano nacional elementos que favorecieron ese consenso. Así, la delimitación de la ciudadanía, el establecimiento de la igualdad civil y de derechos y obligaciones compartidos, la institucionalización de los derechos políticos y la distinción entre ciudadanos y extranjeros contribuyeron a articular una doctrina de la soberanía nacional que vinculaba ciudadanía y nacionalidad (Brubaker 1992). Dos caras, según Bauböck (2006), de la misma moneda: si la nacionalidad atañe a los aspectos internos y externos de la relación entre un individuo y un Estado soberano, 
la ciudadanía pertenece al aspecto interno de esa relación, regulada por leyes domésticas.

Desde que en la antigüedad se contemplaba al ciudadano como un sujeto portador de la doble condición de gobernante y gobernado 5 hasta la época moderna, el proceso de formación de la ciudadanía habría pasado, según la clásica secuencia de Marshall (1992), por tres grandes fases históricas: una primera que representa la conquista de derechos civiles vinculados a la libertad individual; una segunda en la que se adquieren los derechos políticos, fundamentalmente a través del voto, y una tercera, ya en el siglo $X X$, en la que se institucionalizan los derechos sociales que redistribuyen entre los ciudadanos los recursos económicos y sociales. En la esencia del Estado nación estaría, por tanto, la institucionalización de la ciudadanía: la integración de todos los habitantes de un territorio en una comunidad política que reconoce la igualdad (Castles y Davidson 2000). No obstante, los grandes movimientos de población y la globalización de los procesos económicos de las últimas décadas complican este modelo y abren el debate de la ciudadanía hacia otras direcciones que trascienden el esquema clásico del Estado nación: hablamos ahora de ciudadanía multicultural, ciudadanía universal, ciudadanía postnacional o ciudadanías de residencia, nuevas acepciones que subrayan su carácter complejo y dinámico, poniendo en evidencia la fragilidad de los límites entre nacional y extranjero.

En países con un gran peso de población inmigrante, como Estados Unidos, se ha observado cómo los límites culturales de la identidad nacional se han ido ampliando progresivamente, incorporando la ciudadanía como elemento fundamental de esa identidad (Waldinger 2011). Si bien el núcleo central de la ciudadanía sigue formado por los derechos políticos, en la actualidad los Estados establecen políticas de integración y condiciones de acceso a diferentes servicios sociales, conformando un nuevo modelo de ciudadanía contemporánea que posibilita simultáneamente la obtención de la nacionalidad y de derechos sociopolíticos, sin renunciar a unas identificaciones de partida en las que el territorio histórico o la patria, como depositaria de recuerdos históricos, sentimientos compartidos y significados comunes (Smith 1997), se encuentran o compiten con nuevas identidades que se configuran en la vivencia de los lugares de destino.

Además de los enfoques clásicos que han ido incorporando la cuestión de la ciudadanía a los estudios migratorios (Castles y Davidson 2000; Bauböck 2006; Brubaker 1992; Soysal 1994), estudios más recientes muestran que, como consecuencia de estos nuevos procesos, la secuencia de adquisición de derechos se desvía de la formulación de Marshall. Así, estudios sobre los refugiados que llegan a Europa (Wodak 2017) sitúan el acceso al empleo, la vivienda, la educación y la salud en un primer nivel de integración, relegando la adquisición plena de los derechos políticos al último lugar. Ya no se trataría, por tanto, de un proceso de cambio histórico, sino de un rápido proceso de cambio social donde la atribución básica de derechos de ciudadanía a la población extranjera comienza por la adquisición de derechos laborales, continúa con la adquisición de derechos sociales y termina con la adquisición de derechos políticos. Adicionalmente, la naturalización de inmigrantes, junto a la aceptación de la doble nacionalidad como mecanismo de integración (Faist 2001), generan formas de pertenencia parcial y simultánea múltiples (pertenencia a dos países y sociedades) o una doble atribución de derechos políticos (en países de origen y de destino), dando como resultado la presencia de población inmigrante con estatutos legales diversos y, como consecuencia, desajustes entre la nacionalidad y los derechos de ciudadanía.

Además de una institución clave en las sociedades contemporáneas, la ciudadanía sigue siendo el verdadero núcleo de la democracia y de la identidad nacional. Sin embargo, es también un concepto ambivalente, pues implica al mismo tiempo inclusión y exclusión, en tanto determina quiénes están o no dentro de la comunidad política (Castles y Davidson 2000; Brubaker 1992), y genera tensión entre lo individual y lo colectivo, al contemplar al ciudadano simultáneamente como individuo abstraído de sus características culturales y como nacional perteneciente a una comunidad de valores culturales compartidos (Castles y Davidson 2000).

\section{Población INMIGRANTE EN EL EJÉR- CITO ESPAÑOL}

Tradicionalmente, el servicio militar obligatorio ha sido uno de los pilares de la nación. Prestar ese servicio al Estado era considerado una "obligación sagrada" para el ciudadano (Brubaker 1992). Por ello, es presumible que el Ejército, como institución encargada de la defensa de un país que no solo se delimita territorialmente, sino también histórica y culturalmente, condense significados sobre la patria y la nación de especial carga simbólica. Sin embargo, esa obligación se ha ido diluyendo con la profesionalización de los ejércitos en la mayor parte de los países occidentales. En España, el servicio militar obligatorio fue suspendido en 2003 , provocando reajustes legislativos y organizativos en las FF.AA. que tuvieron como consecuencia una fuerte reducción del número de efectivos. Ciertamente, el objetivo de profesionalizar y modernizar el ejército obligó durante esos años a poner en marcha una serie de campañas dirigidas a fomentar el reclutamiento profesional entre los jóvenes.

A pesar de estas campañas, el importante descenso de la natalidad que tuvo lugar en España desde los años ochenta, junto a un mercado laboral en expansión, causaron una reducción drástica en la cantidad 
de jóvenes españoles que optaron por la profesión militar. En esta situación, las mujeres y los inmigrantes se convirtieron en un recurso fundamental para solventar el déficit de efectivos (Hombrado, Olmeda y Del Val, 2007). A partir de 2008, no obstante, con la llegada de la crisis económica y el aumento del desempleo reapareció el interés de los ciudadanos nativos por incorporarse a las FF.AA. El ejército suponía un mercado de trabajo seguro que podía proporcionar una salida laboral a jóvenes españoles con cierta formación académica que tenían dificultades para encontrar empleo. Ello ha afectado cuantitativamente a la población militar de origen extranjero, que ha pasado del 6,7 \% en 2010 a apenas el $1 \%$ en la actualidad. La trayectoria migratoria de este colectivo y su específica situación vital (trabajando en el ejército de un país diferente al de origen) constituirán elementos de especial interés para el estudio de su representación de la pertenencia nacional.

\section{Metodología}

La investigación tiene una orientación cualitativa basada en la realización de grupos de discusión, cuya pertinencia para captar actitudes, representaciones e imágenes sociales está ampliamente justificada 6 . Esta metodología articula distintos elementos: los sujetos portadores de una determinada percepción, las variables que definen su contexto social y el material lingüístico producido por la enunciación de sus discursos. Si bien los estudios cuantitativos son fundamentales para abordar las dinámicas de los flujos migratorios, desde el campo de las migraciones también se ha reconocido la utilidad de los grupos de discusión para explorar el proceso por el que los inmigrantes se representan e interpretan la ciudadanía a través de sus vivencias (Bauböck 2006: 31). Analizar estas actitudes sociales nos acerca a la comprensión del proceso de incorporación de los inmigrantes, así como a los símbolos, representaciones y valores que le dan sentido. También, como muestra Béjar (2007), este análisis permite el estudio en profundidad de significados relacionados con la pertenencia a la nación y la ciudadanía.

Se trata de una apuesta por un enfoque cercano a la microsociología que parte del análisis del discurso resultante de la interacción entre un colectivo de iguales, la tropa, para aproximarnos al conocimiento de su proceso de integración ciudadana. La importante presencia en España del colectivo latinoamericano entre la población inmigrante (muy notoria igualmente entre los inmigrantes de las FF.AA.) justifica que el estudio se centre específicamente en este grupo. Ello permitirá comparaciones con Estados Unidos en trabajos posteriores, pues en ambas sociedades la población de origen latinoamericano es mayoritaria entre la población inmigrante.
Los grupos se realizaron con el apoyo del Instituto General Gutiérrez Mellado de la UNED y los trabajos de contacto, así como los lugares para la celebración de las reuniones (en casi todos los casos, locales propios de la tropa o de uso institucional) fueron facilitados por el Ministerio de Defensa. Todos los grupos se realizaron en la Comunidad de Madrid.

Al configurar los grupos se tuvo en cuenta el sexo (un grupo de hombres, un grupo de mujeres y tres grupos mixtos) y el tiempo de residencia en España (dos grupos con menos de 10 años, y tres grupos con más de 10 años). La edad de los participantes osciló entre los 18 y los 35 años.

Las reuniones duraron entre una hora y media y dos horas y fueron grabadas y transcritas en su literalidad. La dinámica propuesta por los moderadores fue abierta, dejando hablar libremente a los participantes en torno al tema de discusión —el significante España- y solo puntualmente se intervino para formular preguntas concretas. Una vez superados los silencios iniciales, la dinámica de las reuniones se desarrolló satisfactoriamente, pues los grupos resultaron muy activos y participativos, en especial el formado por mujeres (RG5). No cabe duda de que la homogeneidad etaria, cultural y ocupacional (todos los integrantes compartían un mismo estatus en la escala) facilitó la fluidez del discurso, contrarrestando dos posibles efectos perniciosos derivados de la situación de investigación en una institución total: a) que la presencia de asimetrías jerárquicas condicionara el discurso, reduciéndolo a una mera enumeración de puntos comunes y b) que se reprodujera el ya clásico recelo entre civiles y militares, habitual en los estudios sobre Fuerzas Armadas y sociedad. En este sentido, tan solo hubo alguna tensión inicial en RG3 ante el recelo de uno los participantes hacia los investigadores -civiles y externos a la institución-que moderaban el grupo. Cuando se aclaró que el Instituto General Gutiérrez Mellado forma parte de la Universidad y colabora con el Ministerio de Defensa, se relajó la tensión y el grupo comenzó a hablar con normalidad. La realización de los grupos en el seno de la institución militar terminó favoreciendo la buena marcha de las reuniones, pues ello contribuyó a avalar la investigación disipando la posible desconfianza de los participantes. Por otro lado, como suele ocurrir al desarrollarse la dinámica grupal, los discursos se desarrollaron con libertad y espontaneidad, sin evitar temas sensibles o comprometidos como la situación política, la valoración de su situación personal o las críticas hacia determinados mandos. Sin duda, podemos decir que su situación como miembros de un ejército profesional con derechos políticos y laborales equivalentes a los de otros colectivos civiles contribuyó al clima abierto de las reuniones. 
Tabla 1.

Características de los grupos de discusión

\begin{tabular}{|c|c|c|}
\hline \multicolumn{3}{|c|}{ CARACTERÍSTICAS DE LOS GRUPOS DE DISCUSIÓN } \\
\hline RG1: & $\begin{array}{l}\text { Sexo: varones y mujeres } \\
\text { Tiempo de residencia en España: menos de } 10 \text { años } \\
\text { Edad: } 18 \text { a } 29 \text { años } \\
\text { Ocupación: tropa } \\
\text { Lugar de realización: Madrid, Cuatro Vientos }\end{array}$ & 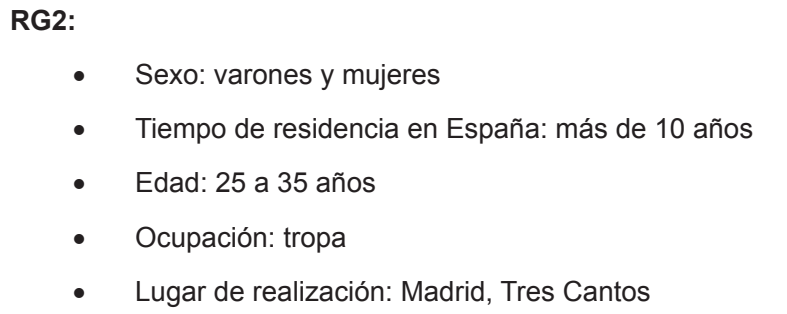 \\
\hline RG3: & $\begin{array}{l}\text { Sexo: varones } \\
\text { Tiempo de residencia en España: más de } 10 \text { años } \\
\text { Edad: } 25 \text { a } 35 \text { años } \\
\text { Ocupación: tropa } \\
\text { Lugar de realización: Madrid, Torrejón de Ardoz }\end{array}$ & $\begin{array}{ll}\text { RG4: } & \\
\text { - } & \text { Sexo: varones y mujeres } \\
\text { - } & \text { Tiempo de residencia en España: menos de } 10 \text { años } \\
\text { - } & \text { Edad: } 18 \text { a } 29 \text { años } \\
\text { - Ocupación: tropa } \\
\text { - Lugar de realización: Madrid, Torrejón de Ardoz }\end{array}$ \\
\hline RG5: & $\begin{array}{l}\text { Sexo: mujeres } \\
\text { Tiempo de residencia en España: más de } 10 \text { años } \\
\text { Edad: } 18 \text { a } 29 \text { años } \\
\text { Ocupación: tropa } \\
\text { Lugar de realización: Madrid, Torrejón de Ardoz }\end{array}$ & \\
\hline
\end{tabular}

\section{RESUltados: EL DISCURSO DE LOS MILITARES INMIGRANTES EN EL EJÉR- CITO ESPAÑOL}

Comenzaremos por describir el proceso migratorio de los participantes desde su propia experiencia. Ello permitirá poner en contexto el análisis que se realizará a continuación sobre las distintas dimensiones que conforman su representación del sentimiento nacional. Finalmente, se abordará el mapa de posiciones sociales sobre su sentido de nación y ciudadanía.

\section{El proceso migratorio}

La emigración desde los países de origen consiste casi siempre en un movimiento familiar protagonizado por los progenitores, muy frecuentemente por la "madre". Durante el final de la década de los noventa y el comienzo de la siguiente, personas con cargas familiares llegaron a España desde otros países, generalmente en solitario, para progresar económicamente y encontrar un futuro mejor para sus familias. Es frecuente describir cómo la madre llegó primero y trabajó muy duro "buscándose la vida" hasta que pudo reunir los recursos suficientes para traer a su/s hijo/s aprovechando la bonanza que durante esos años impulsaba la inmigración a nuestro país ["Mi madre igual, vino aquí sola sin conocer a nadie y buscándose la vida por ahí, y me decía que dormía en habitaciones, en casas con quince, veinte personas...". RG4, 12]. Ello atrajo inmigrantes que pudieron generar recursos ("ganaban bien") y, al regresar a sus países, por un efecto demostración, animaban a otros compatriotas a seguir el mismo sendero en un momento en que no había excesivas trabas para ello ["Había mucho trabajo y necesitaban (...) y había muy poca gente para trabajar y había mucho trabajo, todo el mundo decía: si hablas español es más fácil entrar...". RG1, 8]

Por eso, muchos de los militares inmigrantes llegaron a edades muy tempranas, cuando eran niños o adolescentes. En estos casos las dificultades iniciales se traducen en sentimientos de desarraigo ("no tenía amigos") en el colegio o el instituto, sintiéndose con frecuencia desplazados por sus otros compañeros ["Una cosa que se me quedó muy grabada fue una niña que se me acercó, sin mala intención y me dijo ¿en tu país hay coches?". RG1, 30]. Sin embargo, han establecido con el paso del tiempo redes de amistad, lazos afectivos, normalizando su vida en España, donde no parecen tener hoy en día problemas de adaptación. Aquellos que llegaron a edades adultas encontraron dificultades específicas durante sus primeros años en España, sobre todo quienes (con frecuencia mujeres) también vinieron con hijos o cargas familiares, siguiendo en muchos casos a sus parejas, en la búsqueda -nuevamente- de un futuro mejor en términos de seguridad y prosperidad económica ["Me quedé embarazada, al año y algo, conocí a un chico y fue el que me dio la oportunidad, me dijo: 'Yo me voy a España, si tú quieres te vienes conmigo' $y$ todo eso. $Y$ al final me vine con él...". RG5, 8]. Esta migración adulta también pue- 
de deberse a un reagrupamiento familiar, fundamentalmente con progenitores y hermanos.

En cualquier caso, los motivos iniciales de su migración a España se relacionan con objetivos pragmáticos y personales. Son frecuentes las alusiones a la vida personal, a la búsqueda de un futuro mejor para "mis hijos", "mi familia", a ganar en calidad de vida, a vivir en un entorno mejor y más seguro. La elección de una carrera militar se debe más a la oportunidad laboral y a las facilidades que la permanencia en el ejército puede suponer para obtener la nacionalidad española, que a una verdadera vocación ["Y tuve que buscar una salida y me metí al ejército y demás...". RG5, 6]. Aunque a veces, sobre todo en el caso de las mujeres, se alude al "modelo" o "ejemplo" que otros familiares varones, también militares (abuelo, padre, hermano), ha supuesto en su vocación y voluntad de pertenecer al ejército.

Escapar de situaciones de conflicto o inseguridad, intentar progresar económicamente, disfrutar de una mayor calidad de vida y tener más oportunidades para ellos y sus familias es lo que finalmente les incita, no solo a emigrar a España, sino a quedarse y construir su vida aquí. ¿Y por qué España y no otro país? Se señala que el motivo fundamental es la lengua, eso facilita las cosas. Pero también, y una vez establecidos, es difícil volver a sus países de origen para algo más que unas vacaciones o una visita a otros familiares que ahora ocupan otro lugar en sus vidas, más distante y menos importante en sus vínculos afectivos ["Pero vamos, que me he adaptado bastante bien... También es que toda mi familia está aquí. En Colombia tengo muy poca gente, mi abuelo y poco más. Entonces tampoco...". RG4, 6]. Veamos ahora cómo este proceso puede influir en su construcción de la identidad nacional.

\section{El sentimiento nacional}

Las líneas antes descritas sobre el proceso migratorio nos ayudarán a contextualizar el significado que para los participantes tiene el sentimiento de pertenencia a la nación. Este análisis se despliega en distintas dimensiones: en primer lugar, la idea de un territorio, la patria, más simbólico que geográfi$\mathrm{co}$, donde se moldean las primeras vivencias y recuerdos; en segundo lugar, el aprendizaje (esté o no interiorizado) de un relato o mito acerca de la construcción de la nación; finalmente, el apego emocional al lugar donde se desarrollan las relaciones afectivas familiares o sociales. En la intersección de todas ellas encontraremos los matices y contradicciones inherentes al discurso sobre el sentimiento nacional de los militares inmigrantes en el ejército español.

\section{El patriotismo como elemento disruptivo}

La patria es un significante ligado no tanto a la nación, sino al vínculo afectivo y cultural que se mantiene con ella. Se asocia discursivamente, por tanto, al sentimiento nacional. El patriotismo aparece ligado al amor por la tierra de la infancia, de la familia, la tierra a la que "se pertenece". Es algo más que la defensa de un territorio ["El patriotismo da sentido de pertenencia... tú sigues siendo de tu país y luchas por lo tuyo...". RG1, 43] y, en su dimensión emocional y positiva, surge (se hace consciente) cuando se abandona el país de origen ["El patriotismo te nace, te sale cuando tú emigras a otro país". RG2, 24].

Sin embargo, las contradicciones surgen al pasar de una patria a otra: en un primer momento se justifica la defensa de las fronteras y de la unidad nacional que se asienta sobre el territorio, pero seguidamente esto se pone en cuestión ante el deseo o la necesidad de conseguir, a través de la migración, una experiencia vital en otra patria ["Las barreras entre países son malísimas, ¿vale?”. RG1, 43]. Finalmente, esta termina siendo un lugar en el que vivir, aunque no sea definitivo, y el patriotismo de origen, aunque interiorizado desde la infancia, resultará un discurso más bien anacrónico que pone barreras y puede obstaculizar las estrategias vitales de los inmigrantes ["Es tu país, cercado, y tienes que quedarte ahí..." RG1, 45], sobre todo las de aquellos que están en proceso de obtención o ya cuentan con la doble nacionalidad: el amor a la patria no está por encima, como veremos, de los derechos adquiridos tanto en sus países de origen como en España.

En efecto, aunque las rutinas patrióticas aprendidas obligatoriamente en la escuela de sus países natales generan un habitus que refuerza el sentido de pertenencia y favorece la incorporación a la sociedad, pueden suponer "aquí" una dificultad para la integración ["Se queda la gente con ese patriotismo... sigue siendo muy ecuatoriana y solo se junta con ecuatorianas, formando un gueto". RG1, 42]. Por tanto, al fundirse y confundirse con la necesidad de integración en el país donde se vive, el patriotismo funciona como un elemento disruptivo que genera obstáculos y contradicciones en la nueva sociedad ["Si a mí me parece bien ese sentimiento de patriotismo. La pena es de que en la cabeza de las personas solo está la patria, de que no abandonamos la patria". RG4, 20].

Este arraigo se hace evidente cuando los participantes abordan el aprendizaje de mitos y símbolos patrios en la escuela de sus respectivos países. Sin duda, el proceso de construcción de las naciones latinoamericanas ha dejado profunda huella en el modo de expresar el sentimiento nacional; en el fondo, los símbolos patrios son fundamentales para tener una identidad ["Estudiar los símbolos patrios, estudiar todo de dónde viene... es obligatorio, entonces nace un sentimiento". RG2, 23]. Sin embargo, en la discusión aparece por momentos una suerte de deconstrucción del relato nacional en el que se cuestiona la veracidad y el sentido de esos mitos nacionales ["El niño Erver... ¿quién era? Supuestamente un gran libertador. Pero si estudias la historia verás que ese 
chaval murió de una diarrea en su casa porque era hijo de españoles bien y nunca fue a la guerra (...) El patriotismo es una gran mentira que nos meten en las repúblicas jóvenes". RG1, 42] ${ }^{7}$. Esta relativización se atribuye al viaje, a la experiencia migratoria, a una nueva situación que les proporciona consciencia y reflexión crítica sobre el relato patriótico inculcado en sus países.

Sin embargo, ello no limita la eficacia de los símbolos, aunque solo sea por la extrañeza que les produce su escasa presencia en España, un país en el que no existe educación patriótica en las escuelas. Consideran que el sentimiento patriótico de los españoles es inferior al de los países americanos ["Nos importa más el amor a nuestra patria”. RG2, 24] y se asombran de que la mayoría de los españoles desconozca el origen de su himno o su bandera nacional, que parecen exhibirse únicamente en eventos deportivos ${ }^{8} \mathrm{u}$ otras muestras de lo que algunos autores han denominado "nacionalismo banal" (Billig 1995). Son conscientes de que esta escasa visibilidad no solo se debe a la falta de educación patriótica en las escuelas españolas, sino a la connotación política de los símbolos nacionales, que se asocian a las secuelas de la guerra civil ["Está claro que viene por el tema del franquismo, eso está claro". RG3, 36]. En sus países, por el contrario, la bandera nacional está asociada a las guerras de la independencia, a la conquista por la libertad o a gestas heroicas y ello tiene, obviamente, otras connotaciones.

Sin embargo, ¿han desarrollado —o pueden llegar a desarrollar- un patriotismo español? Es interesante observar que la dimensión emocional de la patria originaria se atempera al trasladar "aquí" ese discurso. Si bien, quizás por la necesidad más o menos consciente de expresar ante el grupo su identificación con España, algunos participantes (sobre todo los que llevan aquí más tiempo) manifestaron desde el comienzo que sentían un fuerte sentimiento de pertenencia a España ["Yo me siento más español que ninguno, te lo digo (...) yo sí, yo quiero mucho a España”. RG1, 21], el discurso sobre el patriotismo español se desarrolla en términos mucho más racionales e instrumentales ["Patria es donde una está, y donde uno está haciendo las cosas, ¿no?... Yo, en este aspecto no me rayo la cabeza de pensar 'tú eres español, o eres colombiano y tal'". RG4, 20]. La patria es el lugar donde uno "está" haciendo "las cosas", es decir, donde desarrolla su vida y lo necesario para mantenerla. Esta ambivalencia entre la dimensión emocional y pragmática de su percepción sobre la patria se proyecta hacia sus expectativas sobre la doble nacionalidad.

\section{Doble nacionalidad, doble ciudadanía}

En general, los estudios empíricos sobre nacionalidad y ciudadanía señalan que la posibilidad de una doble adscripción incrementa la propensión entre los inmigrantes a naturalizarse en el país de acogida, pero manteniendo también la nacionalidad de origen (Faist, 2001). Los vínculos trans-estatales de los migrantes en un mundo globalizado conceden un plus de valor a la posesión de esa doble ciudadanía, algo factible para los inmigrantes latinoamericanos, dado que en sus países esta se aceptada sin demasiadas dificultades.

Buena parte de los participantes tenían ya concedida la nacionalidad española, mientras otros estaban en proceso de tramitación. Esa doble pertenencia que implica no renunciar a la nacionalidad de origen se justifica en términos pragmáticos ["Si no eres nacional y quieres ir, por ejemplo, al Machu Picchu, pues te cobran más dinero por ser extranjero...". RG2, 12]. A la vez, consideran de forma entusiasta las ventajas de utilizar la nacionalidad española para viajar por Europa o por el resto del mundo. Hay un cálculo económico en todo ello que choca con el relato patriótico al que están acostumbrados ["Si eres de España... abre puertas. Con la nacionalidad colombiana es imposible". RG2, 12]. Junto con esa visión más instrumental, despliegan también la satisfacción de ser considerado español, un sentimiento que procede más del éxito personal que del sentido de pertenencia a la comunidad y está más próximo, por tanto, a un modelo de ciudanía liberal que a un modelo de ciudadanía republicano ["También es un orgullo tenerla (la nacionalidad española), en el sentido de que, quieras o no, a uno le ha ayudado a progresar". RG, 12]. El reconocimiento por el país de acogida se vive con orgullo, pues implica alcanzar unas metas profesionales y obtener unos derechos ciudadanos que les igualan a la población autóctona, permitiéndoles reconocerse también como españoles.

Sin embargo, como ya avanzamos anteriormente, la obtención de la nacionalidad no implica necesariamente un mayor patriotismo o sentimiento de españolidad; lo que se obtienen son fundamentalmente ventajas materiales que se ejemplifican con gran frecuencia en la facilidad para "viajar por el mundo". De hecho, al abordar la doble nacionalidad, los participantes asumen claramente que son extranjeros nacionalizados, pues utilizan el término 'nacionalizado' como si realmente no fueran españoles, como si la identidad nacional fuese solo una, la original, aquella donde se encuentran sus raíces familiares. El sentimiento de pertenencia a la nación se desvela como algo más complejo que el reconocimiento por el Estado de unos derechos. Y aunque en algunos casos reclaman que además de "nacionalizados" son también "españoles", su discurso trasluce la falta de sensibilidad de algunos sectores de la población nativa, cuyas reacciones contribuyen a incrementar esa confusión ["Eso me lo recalcan mis compañeros españoles: 'oye que tú no eres de aquí', ya lo sé, pero soy español, ¿no?”. RG2, 12]. Incluso una de las participantes no es capaz de concluir la frase en la que desea manifestar su orgullo por ser española: "yo estoy súper contenta y súper orgullosa de ser esp..., de tener mi nacionalidad" (RG2, 18). 
Finalmente, la obtención de la nacionalidad española tiene también una relación directa con su permanencia en el ejército: no solo constituye un requisito para seguir trabajando en esa institución, sino que llega a observarse como una especie de "compensación" por defender un país que "no es el suyo" ["(...) que estamos sirviendo a un país que no es el nuestro, lo suyo es eso, tener la nacionalidad". RG2, 13].

La identidad nacional no se proporciona a través de una tarjeta de residencia o del documento nacional de identidad concedido por el Estado que les acoge, incluso con los derechos de ciudadanía que ello puede proporcionar. La identidad nacional remite a la trayectoria vital, a la memoria. La patria se identifica con los recuerdos y allí donde se forjan es donde se genera la identidad. Por eso, aquellos que llegaron muy jóvenes, a pesar de ser conscientes de sus orígenes, se identifican con España a través de los vínculos afectivos, familiares y sociales que han creado aquí: la familia de "aquí" se diferencia claramente de la familia de "alli". Este será un elemento de anclaje fundamental que modulará la voluntad de retorno. Quienes llevan más tiempo en España tienen claras sus preferencias al respecto ["Es que toda mi infancia, la adolescencia, nuestros amigos están hechos aquí, entonces supongo que eso también es un punto determinante para uno decidir si se va o no se va". RG2, 4], al igual que quienes, independientemente del tiempo de residencia, consideran que en España sus hijos podrán tener un futuro más próspero y seguro ["Tengo mi familia acá también... y sin ganas de volver". RG5, 2].

En definitiva, la formación del sentimiento nacional es un proceso reflexivo en el que interviene no solo el inmigrante, sino también la actitud del autóctono y las instituciones que deben procurar unas condiciones para el desarrollo de la ciudadanía. Desde su experiencia consideran que España, en comparación con otros países occidentales, todavía no ha conseguido aceptar que ya es una sociedad multiétnica y multicultural ["En Estados Unidos también hay racismo... Pero aquí todavía hay cierto escepticismo con el tema de que un latino pueda ser igual que un español". RG3, 23]. Su percepción de la posición que ocupan en la escala social tampoco favorece la integración, puesto que les sitúa en el escalafón más bajo como miembros de la "clase social inmigrante", una clase que se percibe inferior a la clase obrera nacional. El orgullo por ser español se enfrenta, entonces, a la contradicción de aceptar implícitamente formar parte de los puestos más bajos de la sociedad. Puede que ahí encontremos parte del pudor a reconocer que, en relación con España, se es algo más que un extranjero nacionalizado.

En todo caso, también se señala que la situación ha ido mejorando ["Ahora están aceptándonos un poco más en la sociedad, no solo en el ejército". RG2, 16]. Tan solo la dificultad para promocionar en el ejér- cito, debida al aumento en los últimos años de la concurrencia de candidatos autóctonos que cuentan con mayor formación académica y, por tanto, con mayores posibilidades para ello, genera incertidumbres laborales e incita al colectivo a replantearse su permanencia en las FF.AA. españolas de cara al futuro.

\section{POSICIONES SOBRE NACIÓN Y CIUDA- DANÍA}

Como ya se ha comentado, la extensión del proceso globalizador ha introducido nuevas y complejas dimensiones en el concepto de ciudadanía. La idea de que los cambios jurídicos y sociales que acompañan este proceso habrían transformado a millones de personas en ciudadanos globales, ha sido motivo de fuertes debates (Sassen 2014; Joppke 2010; Faist 2001; Soysal 1994). La visión de una ciudadanía global que junto a nuevos actores (grandes corporaciones transnacionales) limita el papel del Estado, podría haber dibujado una nueva ciudadanía más implicada en el consumo como manifestación del logro personal que en el desarrollo de valores democráticos (Castles y Davidson 2000). En todo caso, el debate sigue abierto entre aquellos que vieron el nacimiento de una nueva ciudadanía más vinculada a las instituciones supranacionales que a la pertenencia nacional (Soysal 1994) y quienes sostienen que el Estado nación es todavía la referencia clave de la ciudadanía (Joppke 2010; Schnapper 2001).

Sin entrar, lógicamente, en este debate, los grupos desarrollan ciertos elementos que amplían o aclaran estos puntos de vista. Estos elementos permiten desplegar el mapa de posiciones discursivas sobre el sentimiento nacional que relacionan la dimensión territorial de la nación con la dimensión ciudadana. No todas las posiciones tienen igual realidad ni intensidad en el discurso colectivo, ni tampoco constituyen discursos estancos que no puedan generar contradicciones. Pero su intersección nos permite dibujar estas posiciones en un continuo delimitado por dos ejes que modulan, según su intensidad, la importancia de esas dimensiones. Este mapa permitirá, no solo ubicar una posición respecto a las demás, sino visibilizar aquellas que tienen mayor presencia en el discurso. Describiremos, en primer lugar, las distintas posiciones para luego observar gráficamente su relación.

En el eje que alude a la dimensión territorial de la nación, encontramos un continuo que va desde una posición local hasta una posición transnacional. La posición local es aquella que vincula los sentimientos nacionales a la tierra de nacimiento, a la tierra de los recuerdos y vivencias de la infancia. Estas imágenes tienen un peso emocional importante a la hora de construir una identidad, pues lo local no solo funciona como "el depositario intermediado de lo nacional", sino que constituye el espacio primigenio generador de identidad nacional (Quiroga 2013: 23). En 
esta posición se situarían aquellos que han llegado a España en edad adulta y tuvieron en sus países de origen (muchos procedentes de entornos rurales) su proceso de socialización y sus relaciones familiares más próximas. En este caso, la posición local podría dificultar la incorporación o la construcción de nuevos vínculos afectivos separados del sentimiento nacional de origen. Pero, alternativamente, esta posición comprendería también a quienes han llegado muy jóvenes a España, se han socializado aquí y se sienten más españoles que del país de origen. Los recuerdos están, en este caso, vinculados al país de acogida, donde la familia y las actividades desarrolladas en un contexto de proximidad constituyen el verdadero anclaje nacional; en palabras de Edmund Burke: "de las familias pasamos al vecindario, a las gentes que frecuentamos y a los lugares de nuestra provincia que amamos" (Schnapper 2001: 88).

En el otro extremo encontramos la posición transnacional, que corresponde a la de quienes ya no se consideran ni de "allí", ni de "aquí". Como se ha señalado, las migraciones y los fenómenos de la globalización han podido socavar la significación política de los Estados nacionales y sus fronteras. Ello implica una superposición de pertenecías entre jurisdicciones territoriales separadas que difuminan las fronteras políticas (Bauböck 2006). Una pertenencia postnacional a la que también ha contribuido el reconocimiento de derechos fundamentales (Soysal 1994) por Naciones Unidas o la Unión Europea. Estos derechos han facilitado la accesibilidad de la experiencia transnacional a capas amplias de la población, pero el viaje no es inocente y produce una sensación de extrañamiento. El sentimiento de pertenencia a la comunidad de origen ha desaparecido o se ha difuminado tanto que apenas es reconocible [“(...) no eres ni un sitio, ni de otro. Eres como del mundo, te sientes español y colombiano, pero en realidad no eres ninguna de las dos cosas...". RG2, 37], y ello tampoco implica una identidad nacional fuerte con el país de acogida ["O sea, ya no me siento, ya no sé ni de dónde soy, en verdad (risas), de allá, de acá...”. RG5, 4].

Entre los dos extremos encontramos dos posiciones intermedias, nacional español y nacional europeo, muy presentes en el discurso. Estas dos posiciones implican cierta integración con el eje de ciudadanía, pues en ellas se entremezclan, como no puede ser de otra forma, actitudes adaptativas hacia la vida y cultura del país de acogida con otras más instrumentales orientadas al logro personal. Para el nacional español, los recuerdos de la infancia, tan importantes en la posición local, no suponen rémoras para un proceso de incorporación al nuevo país en el que el respeto y el orgullo por los orígenes no impide en absoluto el deseo y la satisfacción por ser un ciudadano español que ha podido culminar sus expectativas personales y laborales, desarrolla aquí su vida y goza de los mismos derechos que los ciudadanos autóctonos ["Yo llevo aquí desde los once años; me siento ecuatoriano, pero a la vez me siento también español (...). De hecho, tampoco querría regresarme a mi país, porque, bueno, en verdad yo también tengo aquí a mi familia, tengo aquí a mi pareja, tengo aquí todo. Y aquí, como dicen mis compañeros, aquí voy a morir". RG2, 39]. La posición europea, en cambio, se acerca a la posición transnacional, pero delimitando algo más el ámbito geográfico, por lo que se aproxima más a la experiencia real de los participantes. La posibilidad de obtener la doble nacionalidad junto al reconocimiento, gracias a ella, de la libertad para moverse libremente por Europa, sitúa las expectativas vitales hacia lo que la Unión Europea puede representar en términos de formación y calidad de vida para el futuro de sus hijos. España es el lugar donde actualmente desarrollan su vida, pero también podría suponer un trampolín para las generaciones venideras ["Si tuviéramos que tirar en algún momento dado para un lado, pues si mi hija tiene que escoger entre Ecuador, por ejemplo, volver a Ecuador y a no sé, algún otro sitio de aquí... yo prefiero que tire para más arriba, de Europa”. RG3, 22].

El segundo eje de ciudadanía modula las posiciones desde las más individualistas hasta las más implicadas con los valores y normas colectivos. Esta última posición, que hemos denominado cívica, comprendería a quienes se sienten plenamente identificados con los derechos y obligaciones que emanan de las instituciones del Estado, cuya labor promueven como ciudadanos integrados. Se trata de una posición débil en todos los grupos, solamente presente en manifestaciones a favor del estado del bienestar y otros servicios que ofrece el Estado, en todo caso siempre como receptores de los mismos [“(...) está el tema de salud; aquí es muy buena, cosa que en nuestro país es muy complicado... Hay buenos médicos y todo, sí, pero es muy escasa la ayuda para la gente de clase media o clases más bajas". RG2, 2]. No hay elaboraciones discursivas sobre la soberanía, los derechos políticos o el control de los asuntos públicos; tan solo aparecen opiniones despectivas hacia los políticos. Tal vez, la debilidad de esta posición se explique, en parte, por la trayectoria sociopolítica de sus propios países, donde resultan más relevantes cuestiones sobre el linaje o la procedencia y composición familiar que las relativas a la gestión de los asuntos públicos. Es dudoso pensar que las luchas contra la metrópoli, por mucho que las ideas de la llustración europea se extendieran por toda América, fuesen revoluciones democráticas. Simplemente habrían supuesto un cambio de élites en el que no se dio cabida a la población indígena o mestiza. Los nuevos Estados habrían nacido con un importante déficit democrático que ha debilitado, o impedido, el desarrollo de un nacionalismo cívico constitucional, y la experiencia de los inmigrantes en 
España, salvo como usuarios de servicios públicos, tampoco parece haberles aportado la motivación para una mayor consciencia y participación política.

Situada en el otro extremo del eje de ciudadanía encontramos la posición individualista, que representa un compromiso extremo por el logro personal que antepone los intereses individuales o de su propio entorno a la colectividad. Aunque, al igual que la posición cívica, tiene importancia en el plano estructural, es en realidad muy débil en el discurso colectivo y solo aparece puntualmente con insinuaciones que sitúan los intereses individuales y familiares por encima del interés general ["Yo ahí lo tengo claro, voy a defender lo mío, claro, por supuesto". RG5, 31].

A medio camino entre esas dos posiciones extremas, la adaptativa es una posición bastante frecuente, que corresponde a quienes han buscado la integración en la sociedad de llegada y, en cierto modo, lo han conseguido ["Uno mismo se gana el respeto, se gana el respeto con el trabajo diario". RG2, 29]. Sin embargo, esta integración no se plantea tanto desde un sentido de pertenencia a la nación o a la comunidad, sino desde los beneficios que ello conlleva para la propia trayectoria vital. Ser aceptado por la sociedad de acogida es un reto personal que se asume sin renunciar a las identidades de partida. Por tanto, en la posición adaptativa la búsqueda -y el logro- del éxito personal y familiar en la incorporación al nuevo país puede convivir con un escaso sentimiento nacional hacia España ["No me he sentido ofendido por nadie. Al contrario, me he hecho querer (...) das una imagen de tu país. Porque, se dice ya, 'los colombianos, buena gente', o ecuatorianos, si vive y hace las cosas bien". RG2, 29].
Por último, la posición instrumental, más allá de cualquier sentimiento patriótico e identitario, plantea la nacionalidad en función de los beneficios materiales que reporta. Si bien se acerca a la posición individualista, se diferencia de esta porque aquí se comprenden y aceptan los mecanismos de la nacionalidad, aunque sea para obtener ventajas materiales de ello. Estamos ante la posición de quienes desean obtener y mantener la doble nacionalidad, no por un especial sentimiento patriótico, sino porque "les abre muchas puertas" tanto en el presente como en un futuro; se trata de una posición muy frecuente y dominante en el discurso. La migración se produce para obtener mejores condiciones económicas y sociales, pero la obtención de la nacionalidad española no impide que, ulteriormente, vuelvan a sus países o vayan a otro, donde seguirían disfrutándola ["Y que me llevo la nacionalidad, me la llevo porque me abre muchas puertas. Hoy estamos aquí, mañana no sabemos dónde. Es una gran ventaja que voy a llevarme de aquí". RG2, 35]. La nacionalidad tiene, por tanto, un evidente sentido utilitario e instrumental ["Yo ahora me he beneficiado mucho de la ecuatoriana y la española; porque al entrar yo siempre a Ecuador, entro con la nacionalidad...". RG3, 19] que está por encima de cualquier dimensión emocional ligada a las connotaciones de la patria.

Gráficamente, podemos representar el mapa de posiciones sobre la identidad nacional en función de un eje horizontal que corresponde con la dimensión territorial de la nación y de un eje vertical relacionado con la ciudadanía.

En el extremo izquierdo del eje territorial aparece la posición local, que corresponde a los sentimien-

Figura 1.

Posiciones sobre nación y ciudanía

Eje:

Ciudadanía

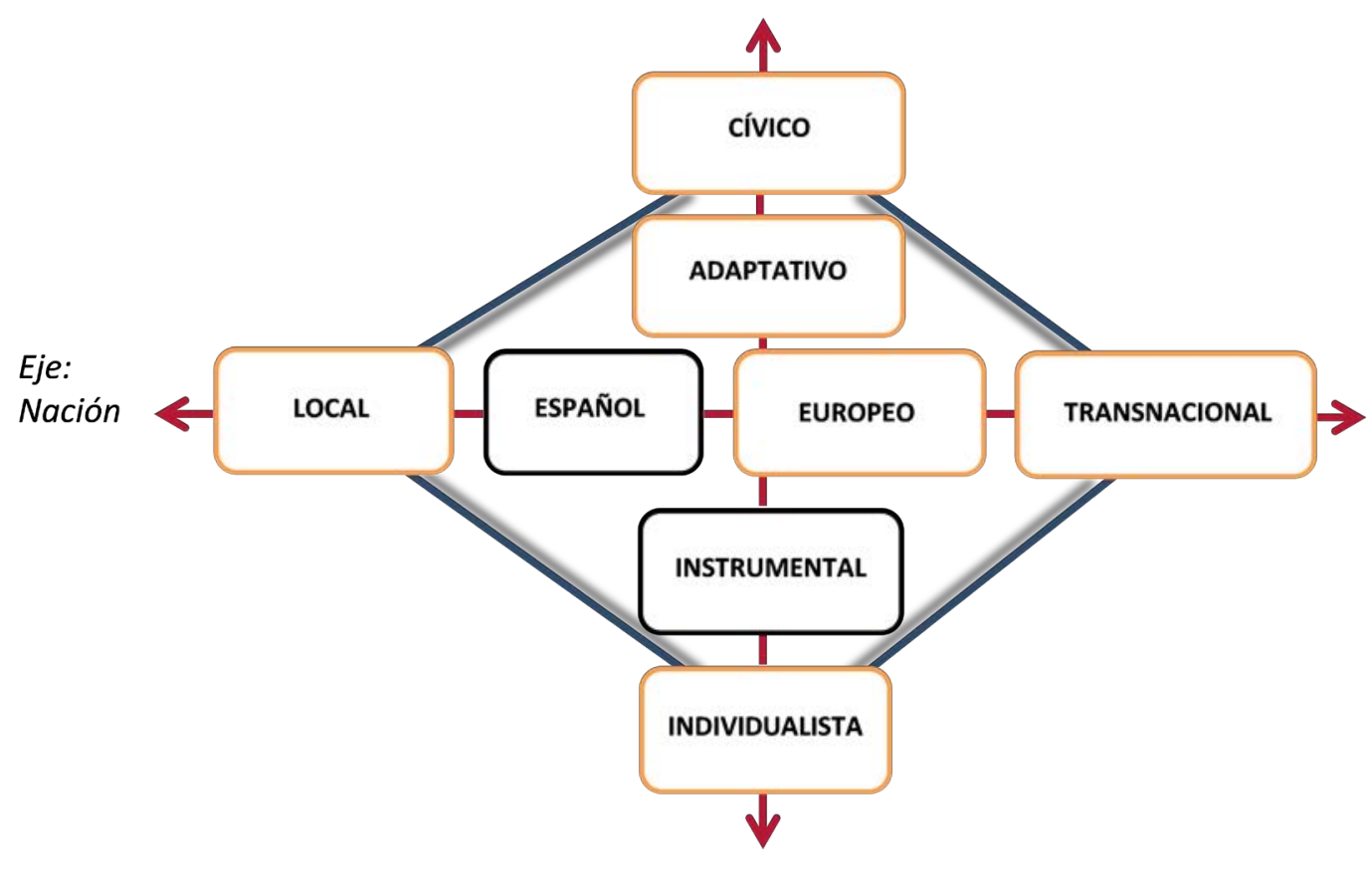

RIS [online] 2019, 77 (2), e127. REVISTA INTERNACIONAL DE SOCIOLOGÍA. ISSN-L: 0034-9712 
tos de identificación con el territorio más fuertes, próximos a la familia y los ancestros. Sobre el eje territorial se pasaría por distintas posiciones, cada vez más alejadas de lo local: nacional español, nacional europeo y, en el extremo derecho, la posición trasnacional.

En el eje vertical o eje de ciudadanía, las posiciones van desde la cívica que aparece en la parte superior y se manifiesta de manera bastante débil en los grupos, hasta la individualista, que hemos situado en la parte inferior. Las posiciones intermedias estarían ocupadas por los individuos que verbalizan el discurso adaptativo e instrumental, siendo esta última una de las posiciones dominantes. Ambas se encuentran muy cercanas al sentimiento nacional español y al europeo. Como podemos observar, las posiciones centrales del mapa (español, adaptativo, europeo e instrumental) participan de las dimensiones de ambos ejes y son dominantes, es decir, son aquellas que tienen mayor presencia en el discurso. En cambio, en los extremos de los ejes aparecen las posiciones discursivas más débiles.

\section{CONCLUSIONES Y ELEMENTOS PARA EL DEBATE}

Diferentes estudios sobre migraciones han observado que el declive de las instituciones nacionales encargadas de promover los valores de la nación y la democracia podría socavar el viejo proyecto republicano de integración de inmigrantes y minorías a través de su participación en los valores políticos comunes. Yasemin Soysal (1994) ha señalado que los procesos de incorporación de inmigrantes se han visto influidos por un discurso global dominante sobre los derechos humanos, desarrollado en paralelo al desvanecimiento de los derechos de ciudadanía adscritos al Estado nación. Otros autores, en cambio, sostienen que el Estado nación continúa siendo el administrador fundamental de la moderna ciudadanía, con independencia de que se hayan ensanchado sus límites o se hayan incorporado nuevos derechos (Joppke 2010). La cuestión es plantear si en un mundo globalizado la ciudadanía puede estar o no conectada a la nacionalidad, es decir, si es posible considerarse miembro de una comunidad política en detrimento de la identidad cultural, o viceversa (Habermas 2008; Bauböck 1994).

Nuestro estudio muestra que las identidades nacionales tradicionales ligadas al territorio de los ancestros se mantienen únicamente en un plano simbólico y emocional, cediendo paso a otras nuevas que sitúan a la nación como un espacio de posibilidad donde se realiza el trabajo, donde se comparte con el entorno relacional cercano, donde se realizan las actividades cotidianas, donde se "hacen las cosas". Una identidad que puede ser incluso transnacional ("se es de aquí y de allí") si se barajan otros desplazamientos que comporten un progreso socioeconómico para el individuo o su familia. La familia funcionará como una metáfora del territorio y constituirá el anclaje fundamental de la vida en nuestro país: la de "allí" ya no tiene la misma relevancia afectiva que la familia construida "aquí". Este será el vínculo que realmente module el deseo de permanecer en España y de no regresar a sus países de origen más que ocasionalmente. Ni siquiera su labor como militares en las Fuerzas Armadas españolas será capaz de introducir un afecto por la nación de mayor entidad que aquel, sobre todo teniendo en cuenta que, independientemente de la vocación que hayan podido desarrollar, el ejército solo era inicialmente una salida laboral para muchos de ellos.

El sentimiento nacional se desdobla en dos dimensiones que, a su vez, modulan su percepción sobre la nación y la ciudadanía. Aunque los inmigrantes no renuncien a la nacionalidad de origen, en el proceso de obtención de la nueva nacionalidad experimentan una profunda transformación que despliega una visión compleja de la nacionalidad y de la ciudadanía. En primer lugar, existe una dimensión emocional ligada a la patria originaria que, aunque se mantiene en mayor o menor grado, ha sufrido un proceso de desmitificación ligado a la experiencia migratoria; el patriotismo, cuando es de origen, se considera un elemento disruptivo que puede dificultar la incorporación a la nueva sociedad. Este proceso no solo se debe a la relativización de los mitos y relatos nacionales, sino a que otra dimensión más pragmática y vinculada a la experiencia vital en el país de destino pasa a primer plano. El desarrollo de un sentimiento nacional hacia España queda afectado, no tanto por un apego emocional a sus símbolos, sino por lo que este país les ha reportado en términos de progreso para sus vidas y las de sus familiares más cercanos, fundamentalmente sus hijos y, si no hay una separación, su pareja. El logro laboral y el desarrollo familiar, como objetivos personales de primer orden, serán realmente los responsables del sentimiento de pertenencia a la nación de destino.

Estas dos dimensiones van a modular las posiciones ideológicas dominantes sobre nación y ciudadanía. La posibilidad de ser español nacionalizado sin renunciar a la nacionalidad de origen es contemplada, de forma más adaptativa o más instrumental, como un beneficio para sus vidas que les permite disfrutar a la vez de ventajas en sus países de origen y de los servicios y derechos de ciudadanía del país de destino, incluso como fórmula ulterior para proporcionar a sus hijos un trampolín hacia Europa. En general, la dimensión socioeconómica de la incorporación (logros laborales, educativos y económicos), prima como factor de integración en 
detrimento de los cambios socioculturales. Dentro de esa dimensión más instrumental tiene especial relevancia el acceso a determinados bienes de consumo (es frecuente la alusión a la compra de un coche o de una casa) como elemento de equiparación y, simbólicamente, de integración con la comunidad autóctona. Una forma de ciudadanía así planteada implicaría revisar, en el contexto de estas migraciones, las últimas etapas de la secuencia de Marshall, dado que su consecución implicaría, en primer lugar, la redistribución de derechos económicos y sociales, relegando a otro orden de prioridad la lucha por los derechos políticos. El orgullo de haber alcanzado una serie de metas de índole personal entre ellas la obtención de la nacionalidad y todo lo que ello proporciona- aparece antes que el orgullo de participar de unos derechos políticos compartidos o de sentirse español.

Pero la integración no va a depender únicamente de las actitudes y percepciones de la población inmigrante. Si bien la mayor parte de los estudios sobre migraciones ponen de manifiesto que la sociedad española se ha adaptado a la llegada masiva de inmigrantes (González 2016), el origen étnico sigue apareciendo en el discurso como un elemento estigmatizador que ha producido sentimientos de ex- trañamiento y desarraigo, al menos durante las primeras etapas de aquellos que llegaron más jóvenes. Sin embargo, con el paso del tiempo han establecido nuevos lazos afectivos que les han permitido normalizar su vida en el país de acogida e inciden poderosamente en su deseo de permanencia. Un deseo que puede ser temporal, pues la identidad nacional más bien diluida de sus países de origen tampoco se sustituye por una identificación fuerte con el país de destino. Se trata de una nacionalidad en tránsito, que permanece en la medida en que el espacio les permita desarrollar sus proyectos vitales con cierto bienestar y seguridad.

\section{AgRADECIMIENTOS}

Agradecemos especialmente el apoyo del Instituto Universitario General Gutiérrez Mellado y del Ministerio de Defensa, al facilitar la realización del trabajo empírico de esta investigación. También queremos agradecer las sugerencias que, durante su elaboración, recibimos de los profesores Roger Waldinger (UCLA) y Ana María López Sala (CSIC), así como los comentarios de los evaluadores que han revisado este trabajo, ya que sus aportaciones han contribuido a mejorarlo y enriquecerlo.

\section{NOTAS}

1. "Una nación es solo la fe en un relato que nos dice quiénes somos, quienes son nuestros antepasados y quiénes no" (Pérez Vejo 2003: 298)

2. Antes de La construcción social de la realidad (Berger y Luckmann 1966), Elie Kedourie había publicado en 1960 Nationalism donde ya plantea el nacionalismo como una doctrina "inventada". En Francia será Bourdieu el representante más destacado de esta visión que contempla la nación como una construcción social y la coloca en el lugar de las representaciones colectivas.

3. Durante la guerra franco-prusiana de 1870 se produjo un importante debate intelectual sobre la fuente de legitimidad de la nación. Del lado prusiano, David Friedrich Strauss defendía la legitimidad de las dinastías, mientras que del lado francés, Ernest Renan consideraba que, frente a ello, estaba el derecho de las nacionalidades basado en la voluntad de los habitantes (Noiriel 2001: 144).

4. "C'est dans nos écoles publiques que se forment la majorité de nos enfants, ce sont elles qui sont et qui doivent être les gar-

diennes par excellence de notre type national" (Durkheim 1963:3).

5. "Lo que conserva en su ser a las ciudades es la igualdad en el dar y el recibir (...) Y así sucede en efecto que todos mandan y gobiernan" (Aristóteles, 1934: 50)

6. Los grupos se realizaron desde la experiencia y la metodología de la Escuela Cualitativista Madrileña: Ibáñez (1986), Ortí (1986), Lucas (2013), Conde (2009), Alonso (1998), Gutiérrez Brito (2008).

7. La leyenda de este héroe de Ecuador es la siguiente: en la batalla de Pichincha (24 de mayo de 1822) un muchacho de 15 años, cuando peleaba por la independencia, resultó mutilado por una bala de cañón, pero, a pesar de las múltiples heridas y mutilaciones, consiguió plantar la bandera nacional y gritar: "iViva el Ecuador!".

8. Durante la realización de los grupos todavía no se había popularizado la exhibición de banderas españolas como reacción a los acontecimientos relacionados con el movimiento independentista catalán. 


\section{RefERENCIAS Bibliográficas}

Álvarez Junco, J. 2016. Dioses útiles. Naciones y nacionalismos. Barcelona: Galaxia Gutemberg.

Alonso, L. E. 1998. La mirada cualitativa en sociología. Madrid: Fundamentos.

Anderson, B. 1983. Imagined Communities, Londres: Verso. Traducción española (1993) Comunidades imaginadas. Reflexiones sobre el origen y la difusión del nacionalismo. México: Fondo de Cultura Económica.

Aristóteles. 1934. La Política. Traducción de Pedro Simón Abril, refundida por Jesús Gil. Madrid: Ediciones Nuestra Raza.

Bauböck, R. 1994. Transnational citizenship: membership and rights in international migration. Aldershot: Edward Elgar.

Bauböck, R. (ed.) 2006. Migration and Citizenship. Amsterdam: University Press.

Béjar, H. 2007. "La investigación cualitativa aplicada al estudio del nacionalismo: el discurso neoespañolista". Empiria 13: 11-34. https://doi. org/10.5944/empiria.13.2007.1157

Berger, P. y T. Luckmann. 1966. La construcción social de la realidad. Buenos Aires: Amorrortu editores.

Billig, M. 1995. Banal Nationalism. London: SAGE.

Brubaker, R. 1992. Citizenship and Nationhood in France and Germany. Cambridge, Mass.: Harvard University Press.

Castles, S. and A. Davidson. 2000. Citizenship and Migration. Basingstoke: MacMillan Press LTD.

Conde, F. 2009. Análisis sociológico del Sistema de discursos. Madrid: CIS.

Cotarelo, R. 2015. La desnacionalización de España. De la nación posible al Estado fallido. Valencia: Tirant Lo Blanch.

Durkheim, E. 1963. L'éducation morale. Paris: PUF.

Faist, T. 2001. "Dual Citizenship as Overlapping Membership". Working paper 3/01. Willy Brandt Series of Working Papers in International Migration and Ethnic Relations, Malmö University, Malmö.

Fusi, J. P. 2016. La patria lejana. El nacionalismo en el siglo XX. Barcelona: Taurus.

Gellner, E. 1997. Naciones y nacionalismo. Madrid: Alianza Editorial.

González Enríquez, C. 2016. "Luces y sombras en la integración de los migrantes en España”. ARI 38/2016-20/5/2016, Real Instituto El Cano, Madrid.
Gutiérrez Brito, J. (2008). Dinámica del grupo de discusión. Madrid: CIS.

Habermas, J. 2008. Más allá del Estado nacional. Madrid: Trotta.

Hobsbawn, E. 2004. Naciones y nacionalismo desde 1780. Barcelona: Crítica.

Hombrado, A., J.A. Olmeda y C. Del Val. 2007. "La incorporación de las mujeres a las FAS: el caso español y su percepción pública en perspectiva comparada". Boletín El Cano 90.

Ibáñez, J. 1986. "Perspectivas de la investigación social: el diseño en la perspectiva estructural." Pp. 31-65, en El Análisis de la realidad social. Métodos y técnicas de investigación, compilado por M. García Ferrando, J. Ibáñez y F. Alvira. Madrid: Alianza Editorial.

Joppke, C. 2010. Citizenship and immigration. Cambridge: Polity Press.

Kedouri, E. 1960. Nationalism. London: Hutchinson.

Lucas, A. de 2013. "Teorías de la interpretación." Pp. 133-166, en Sociología del consumo e Investigación de Mercados. Una guía didáctica, coordinado por J. M. Arribas Macho. Madrid: UNED.

Marshall, T. H. y T. Bottomore. 1992. Ciudadanía y clase social. Madrid: Alianza Editorial.

Morales, A., J. P. Fusi y A. de Blas (dirs.). 2013. Historia de la nación y del nacionalismo español. Barcelona: Galaxia Gutenberg.

Noiriel, G. 2001. État, nation et immigration. Paris : Gallimard.

Ortí, A. 1986. "La apertura y el enfoque cualitativo o estructural: la entrevista abierta semidirectiva y la discusión de grupo," Pp. 153-185, en El Análisis de la realidad social. Métodos y técnicas de investigación, compilado por M. García Ferrando, J. Ibáñez y F. Alvira. Madrid: Alianza Editorial.

Pérez Vejo, T. 2003. "La construcción de las naciones como problema historiográfico: el caso del mundo hispánico". Historia Mexicana 53(2): 275-311.

Pérez Vejo, T. 2010. Elegía criolla. Una reinterpretación de las guerras de Independencia hispanoamericanas. México: Tusquets Editores.

Pérez Vejo. T. 2015. España imaginada. Historia de la invención de una nación. Barcelona: Galaxia Gutenberg.

Quiroga, A. 2013. "La nacionalización en España. Una propuesta teórica”. Ayer 90: 17-38. 
Romero, J. y A. Furió, A. 2015. Historia de las Españas. Valencia: Tirant Humanidades.

Sassen, S. 2014. Inmigrantes y ciudadanos. Madrid: Siglo XXI.

Smith, A.D. 1997. La identidad nacional. Madrid: Trama Editorial.

Schnapper, D. 2001. La comunidad de los ciudadanos. Madrid: Alianza Editorial.

Soysal, Y. 1994. Limits of citizenship. Migrants and Postnational Membership in Europe. Chicago: The University of Chicago Press.

Waldinger, R. 2011. "Transformar a los inmigrantes en nacionales. El caso de Estados Unidos".
Empiria 22: 173-190. Traducción del original "Transforming foreigners into Americans" (2007), en Waters. M.C. \& Ueda R., The New Americans. A Guide to Immigration since 1965. Cambridge: Harvard University Press. https:// doi.org/10.5944/empiria.22.2011.853

Wodak, R. E. 2017. "Integration and culture: from 'communicative competence' to 'competence in plurality'." Pp. 116-137, en The integration of migrants and refugees: an EUI forum on migration, citizenship and demography, editado por R. Bauböck, y M. Tripkovic. European University Institute. https://doi.org/10.2870/30835

JOSÉ MARÍA ARRIBAS es catedrático de Sociología, UNED. Especializado en métodos cualitativos y cuantitativos de investigación social, ha dirigido y participado en diferentes investigaciones sobre cambio y movimientos sociales. Ha publicado diferentes libros y artículos como autor principal o en colaboración, entre otros: La juventud de los ochenta; El proceso de profesionalización de los agricultores; Estadística, sociología y Estado; Historia de la probabilidad y la estadística; Sociología del consumo e investigación de mercados. Ha dirigido tesis doctorales sobre La medida de la opinión pública y La construcción de las categorías de desempleo en Francia y España.

CONSUELO DEL VAL CID es profesora titular de Sociología en la UNED. Especializada como docente en métodos y técnicas de investigación social, ha desarrollado líneas de investigación en opinión pública, conflictos internacionales e instituciones totales, siempre imbuidas de la perspectiva de género. Fruto de estas investigaciones ha publicado, entre otras obras: Opinión pública y opinión publicada: Los españoles y el referéndum de la OTAN; Próximo Oriente: ¿Qué tipo de paz?; Security Threats, Foreign Policy and the Military; Las mujeres militares en España; La incorporación de la mujer a las Fuerzas Armadas: el caso español y su percepción pública en perspectiva comparada.

BEATRIZ MAÑAS RAMíREZ es profesora contratada doctora en el Departamento de Sociología I (UNED), donde imparte docencia en Estadística Social y Métodos de investigación. Su principal línea de investigación se relaciona con el análisis metodológico para el estudio la opinión pública. Entre sus publicaciones, se encuentran: Institutional Research on Public Opinion and Participative devices: From Polls to Public Debate; El recorrido conceptual de la "opinión pública": de ideal político a objeto de control institucional; La medida de la opinión pública. Una mirada sociológica; Los orígenes estadísticos de las encuestas de opinión. 